\title{
El rol del abogado como sujeto obligado a informar y su vinculación con el delito de Lavado de Activos
}

\section{Espitz Beteta Amancio}

Abogado por la Universidad Nacional Hermilio Valdizán de Huánuco. Miembro Fundador del Círculo de Estudios Penales "IURIS PRUDENS" de la

Universidad Nacional Hermilio Valdizán de Huánuco. Presidente del XI Congreso Nacional de Derecho Penal y Criminología-Huánuco.

SUMARIO:

I. Introducción y Planteamiento del problema.

II. El abogado y el delito de Lavado de Activos.

III. Colisión de Deberes.

1. El Deber de informar vs. el Deber de guardar secreto profesional.

2. Alcances y límites de los Deberes en conflicto.

* El artículo fue recibido con fecha 16-07-18. 


\section{RESUMEN:}

La política criminal justifica la expansión del control sobre las libertades de la abogacía. Se manifiesta porque la génesis del delito de lavado de dinero, lleva el lavador a necesariamente prestar un servicio del sistema para transformar el ilícito. En ese sentido, no existe una forma de conseguir una transformación de lo ilícito en lo que se dice sin tener que recurrir a la plataforma legal.

Palabras clave: profesión, deber, informar, secreto profesional, lavado de dinero.

\footnotetext{
ABSTRACT:

Criminal policy justifies the expansion of control over the liberties of the legal profession. It is manifested because the genesis of the crime of money laundering, leads the launderer to necessarily provide a service to transform the illicit. In that sense, there is no way to achieve a transformation of the illicit in what is said without having to resort to the legal platform.

Keywords: occupetion, duty, inform, professional confidenciality, money laundering.
}

\section{INTRODUCCIÓN Y PLANTEAMIENTO DEL PROBLEMA}

En nuestro ordenamiento jurídico penal se reconoce la figura del "sujeto obligado a informar", a partir de la figura delictiva de "omisión de denuncia" contenido en el artículo 407 del Código Penal. Esta disposición, qué duda cabe, es un claro ejemplo de ley penal en blanco, ya que, para su real configuración, debe recurrirse — primero- a los "deberes especiales" que se le atribuye por su "profesión o empleo", y solo a partir de aquella configuración hacerle responder como "sujeto obligado".

La estructura de la figura del "sujeto obligado" siempre ha estado unida a la de los "deberes especiales", no habiendo problema en señalar que quien no cumple un deber positivo, responderá penalmente, si es que aún estando en las posibilidades de cumplir el deber, ha decidido quebran- tarlo. No obstante, cabe señalar que lo antes indicado se construye sobre la base de un solo "deber especial", y es aquél, la única pauta de comportamiento que orienta a la del "sujeto obligado".

Sin embargo, a partir del Decreto Legislativo $1106^{1}$ — Ley para la lucha eficaz contra el lavado de activos y otros delitos relacionados a la minería ilegal y crimen organizado-, y especialmente del Decreto Legislativo 1249, a través del cual se incorpora al abogado como "sujeto obliga$\mathrm{do}^{\prime 2}$, el "deber" que se supone fija la pauta de la conducta del agente, se puede entender desde orientaciones distintas. Lo que significa que la realización de un "deber", hará irrealizable, necesariamente, el otro "deber". Esto debido a que ahora se ha transferido al abogado el "deber de solidaridad" 3 "de informar operaciones sospechosas" que "conozca" o "presuma" peligrosas contra su cliente, dentro de una política de prevención y detección de lavado de activos.

1. Artículo 5.- Omisión de comunicación de operaciones o transacciones sospechosas.

2. Artículo 3.- De los sujetos obligados a informar: "3.1. Son sujetos obloigados a informar y, como tal, están obligados a proporcionar información a que se refiere el artículo $3^{\circ}$ de la Ley $N^{\circ} 27693$, Ley que crea la Unidad d elnteligencia Financiera-Perú e implementar el sistema de prevención de lavado de activos y del financiamiento del terrorismo, las personas naturales y jurídicas siguientes: (...) 29) Los abogados y contadores públicos colegiados, que de manera independiente o en sociedad, realizan o se disponen a realizar en nombre de un tercero o por cuenta de éste, de manera habitual, las siguientes actividades: a) Compra y venta de bienes inmuebles; b) Administración de dinero, valores, cuentas del sistema financiero u otros activos; c) Organización de aportes para la creación, operación o administración de personas jurídicas; d) Creación, administración y/o reorganización de personas jurídicas u otras estructuras jurídicas; e) Compra y venta de acciones o participaciones sociales de personas jurídicas. La información que estos sujetos obligados proprocionan a la UIF-Perú se restringe a aquella que no se encuentra sujeta al secreto profesional." 
En ese sentido, sobre el "deber de informar", resulta importante contraponer el "secreto profesional" ya que ambos orientan una pauta de conducta que busca sancionar el abandono del "rol social" a partir de ámbitos de responsabilidad del abogado que descansan en orillas opuestas. Esto debido a que el artículo 3 del Decreto Legislativo 1249, ampliando el catálogo de sujetos obligados a informar, traslada una pauta de conducta al abogado, convirtiéndolo en sujeto "obligado a informar" conforme al artículo 3 de la Ley 27693, Ley que crea la Unidad de Inteligencias Financiera Perú-UIF; y además, lo conmina a implementar el sistema de prevención de lavado de activos y del financiamiento del terrorismo ${ }^{4}$. Pero a su vez, también señala que el abogado debe guardar el "secreto profesional".

Sin desmerecer otros problemas que surgen de la regulación en mención, y que nos parecen desde luego todos ellos muy importantes, en este trabajo, queremos poner en evidencia que el traslado de "deberes contrarios" a los del "secreto profesional", más allá de convertir al abogado en "sujeto obligado", busca fundamentar un comportamiento "omisivo" que desde la configuración del delito de lavado de activos, pueda entenderse como el abandono del "rol social" o de una "conducta neutra", lo que desde nuestra perspectiva, pretendería justificar la intervención del abogado en el delito de lavado de activos.

\section{EL ABOGADO Y EL DELITO DE LAVADO DE ACTIVOS}

Debido al notorio protagonismo que ha cobrado la figura del abogado en casos reportados como delito de lavado de activos, especialmente de aquellos que intervienen en el sector inmobiliario y financiero como aparente articulación de las modalidades conductuales del delito ${ }^{5}$ - conversión, transferencia, ocultamiento o tenencia-, el Estado, a través de una pauta de conducta, traslada, respecto del abogado, el "deber de informar" situaciones calificadas como "operaciones sospechosas" —riesgos-. Esta preocupación, que desde la política criminal justifica la expansión del control sobre las libertades de la abogacía, se manifiesta porque la génesis del delito de lavado de dinero, lleva al lavador, necesariamente a servirse del sistema lícito para transformar lo ilícito ${ }^{6}$.

Por lo tanto, no existe forma de conseguir una transformación de lo ilícito a lo lícito sin tener que recurrir a la plataforma legal, logrando de esa manera burlar los controles que nuestra política criminal busca combatir eficazmente para prevenir y reprimir las practicas de lavado. Ello se hace posible, por ejemplo, a través de: la compra y venta de bienes inmuebles; la administración de dinero, valores, cuentas del sistema financiero $u$ otros activos; la organización de aportes para la creación, operación o administración de personas jurídicas; la creación,

3. FRISCH, Wolfgang. Derecho penal y solidaridad a la vez, sobre el estado de necesidad y la omisión del deber de socorro. En: Indret, 4/2016. Barcelona: 2016, p. 3: "El concepto lo marcaron el Derecho civil y el Derecho laboral; luego, el concepto adquirió importancia central en el Derecho de la Seguridad Social; a través del principio del Estado social y la concepción del Estado como comunidad solidaria, el concepto alcanza el Derecho constitucional; y hoy lo encontramos en el Derecho transnacional y en el Derecho internacional."

4. Cfr. CEVASCO, Luis Jorge. Encubrimiento y lavado de dinero. Argentina: Fabian J. Di Placido Editor, 2002, p. 107: “(...) Esta norma es incostitucional, en tanto establece una clara responsabilidad objetiva de carácter penal porque carece totalmente de fundamento".

5. Decreto Supremo N020-2017-JUS, Reglamento de la Ley 27693. Artículo 2.- Definiciones: "(...) i) Riesgos de LA/ FT: Posibilidad de que el sujeto obligado sea utilizado para fines de LA/FT. No comprende el riesgo de reputación y el operacional."

6. GARCÍA CAVERO, Percy. Derecho penal económico parte especial. Volumen I, Segunda Edición. Lima: Pacifico Editores, 2015. p. 510. 
administración y/o reorganización de personas jurídicas u otras estructuras jurídicas; la compra y venta de acciones o participaciones sociales de personas jurídicas; con la finalidad de evitar su identificación, se traslada el dinero que se generó con la comisión de un delito previo, al mercado legal.

El delito de lavado de activos, como ya se ha dicho en textos mucho más extensos, consiste en la transformación del dinero ilícitamente obtenido como consecuencia de la comisión de un delito previo a la esfera lícita7. En esa línea argumentativa que se hace para definir al delito de lavado de activos, en nuestro estudio, partimos por asumir que existe una vinculación entre el abogado y el delito de lavado de activos. Porque es evidente que una de las formas en las que aparentemente interviene el abogado sería sirviendo de vehículo para trasladar los activos de la esfera ilícita a una esfera lícita, donde los servicios de este sujeto profesional es contratado por el lavador para hacer posible la incorporación de los activos - generados por la comisión de un delito previo- a la esfera lícita, procurando que no sea posible identificar el verdadero origen de los activos, y de ésta manera, poder concretar alguna modalidad del delito de lavado de dinero.

Como indicamos, el lavador se sirve del andamiaje legal para lograr la incorporación del dinero ílicito al mercado lícito, y siempre que decida hacerlo a través de los servicios profesionales que libremente presta un abogado, recurrirá, por ejemplo: a la compra y venta de bienes inmuebles; a la administración de dinero, valores, cuentas del sistema financiero $u$ otros activos; a la organización de aportes para la creación, operación o administración de per- sonas jurídicas; a la creación, administración y/o reorganización de personas jurídicas u otras estructuras jurídicas; a la compra y venta de acciones o participaciones sociales de personas jurídicas. Para el lavador de dinero, los mecanismos antes señalados son más eficaces para burlar los controles de prevención, procurando trasladar el dinero de una esfera a otra ${ }^{8}$.

\section{COLISIÓN DE DEBERES}

\section{El deber de informar vs. el deber de guardar secreto profesional.}

Una de las variantes que recoge la regulación del delito de lavado de activos es la modalidad "omisiva". Dentro de ésta se incorpora al abogado bajo la cláusula de "sujeto obligado", trasladando sobre aquél deberes positivos consistentes en "informar operaciones sospechosas". Desde nuestra lectura, el fundamentar un castigo por "no informar operaciones sospechosas", para el abogado, colisiona con el deber de "guardar el secreto profesional". Esto debido a que el "conocimiento" de la operación que debe comunicar llega a él como profesional para que mantenga reserva absoluta del dialogo entre abogado-cliente.

Así, consideramos que exigirle al abogado informar sobre operaciones que le han sido confiadas por su cliente, aunque la revelación consista en la de un plan criminal, por ejemplo, lavar dinero, en principio, debe guardarse en secreto profesional, tan igual como un cura lo hace respecto de algún fiel que acude a su iglesia para confesar que va a pecar dando muerte a alguien. Una obligación que se fundamente en el deber de informar tales operaciones sospechosas, constituiría un desmedido e irracio-

\section{Op.Cit., p. 505.}

8. Cabe indicar, que no es el traslado de dinero de una esfera a otra, lo que per se, comunica un significado de relevancia penal. Lo que se busca es poner controles a quienes intervienen en la confección de documentos para llevar adelante el traslado de dinero que presente dudas sobre su origen; es decir, sobre activos que se cuestione su licitud "conociéndose" o "presumiéndose" ilícitos. La sola situación de "traslado de dinero", al margen de los otros componentes necesarios para su real entendimiento, haría arbitraria la medida adoptada sobre los "sujetos abligados", entre ellos, el abogado. 
nal adelantamiento de barreras de control. Por esa razón, el deber que obliga a comportarse de una determinada manera tendría que fundamentarse sobre criterios externos, una posición diferente llevaría a suponer que bastaría que mañana el legislador dijera que todos los que conozcan operaciones sospechosas deben informar de las mismas.

Por otro lado, "el deber de informar" para el abogado, también se exige luego de haber prestado el servicio o ayudado al lavador. En este supuesto, es importante la constatación de una "operación sospechosa" que legitime el deber que se le impone al abogado. En ese sentido, son "operaciones sospechosas" toda maniobra del agente para procurar evitar la identificación de los activos. Aquí, inclusive es posible sostener que - el abogado - es el único profesional al que por sus conocimientos especiales sobre leyes, y la amplitud de su ejercicio sobre éste ámbito - función-, brinda un servicio profesional que garantice un mejor y eficaz servicio -al agente lavador- para "trasladar dinero de una esfera a otra".

Debido a la relación que hace el legislador, entre: "el abogado" y actos de "lavado de dinero"; existe desde nuestra perspectiva una esfera donde la actuación del abogado supone el incremento de un riesgo no permitido. Esto ocurre cuando interviene de forma activa en la confección de la "operación sospechosa". Por esta razón, si bien no se puede evitar que el abogado preste su servicio, el legislador ha optado por dividir la prestación del servicio del abogado en una regular y en una "sospechosa", sobre ésta última es que surge propiamente "la obligación de informar".

\section{Alcances y límites de los deberes en conflicto.}

Hasta antes de la Ley 1249, el abogado estaba fuera del alcance del delito de lavado de activos. Al respecto, la última anotación que se hiciera sobre el abogado en relación al delito de lavado de activos concluía que: "Los servicios que ellos prestan carecen de tipicidad porque no son actos de colocación, transfor- mación u ocultamiento en los términos y alcances que corresponden al ciclo de lavado de activos". Bajo esa conclusión, el Acuerdo Plenario N 03-2010. F.J.: 26, sostiene que: "De allí que el abogado, el médico, los familiares dependientes, los empleados domésticos, los proveedores cotidianos, etc., que se relacionan con el titular de los activos ilícitos originales o reciclados, en ese espacio especifico y neutral, propio de sus negocios standard, no actúan premunidos de esa finalidad, ni proveen a aquél de esa consoldación lucrativa. (...). Por, además, no existe, frente a tales conductas, una necesidad de pena, ni hay riesgos de debilitamiento de la prevención general, ni mucho menos el agente expresa en su conducta requerimientos de prevención especial".

El profesor José Antonio CARO JOHN, en un trabajo titulado: "Los abogados ante el lavado de activos: Recepción de honorarios sucios y deber de confidencialidad", al hacer referencia a una tendencia orientada por incluir como "sujetos obligados" a profesionales independientes, y entre ellos, el abogado; no dudó en sostener que el legislador terminaría regulando las competencias del abogado en el sistema de prevención y detección de lavado de activos. No obstante, el análisis del profesor giraba sobre la recepción de honorarios del abogado como consecuencia de la profesión, y a partir de esa premisa, establecer la relevencia penal del abogado como "sujeto obligado a informar", tomando como referencia el ámbito de protección que a partir del "secreto profesional" la Constitución asegura para el abogado frente a una relacion abogado-cliente. La conclusión estriba en que al no haber restricción normativa alguna sobre el deber de confidencialidad en la relación abogado-cliente, es decir, "existir cuanto menos un deber jurídico plasmado en una norma jurídica que fije la pauta de conducta en este sentido", simplemente, no es posible volcar sobre el abogado los deberes solidarios que sí existen sobre los que hasta ese momento eran considerados "sujetos obligados a informar".

Sin embargo, el ámbito de análisis del rol del abogado, regulado, ahora sí en una norma ju-

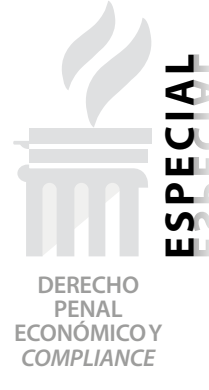

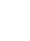


rídica que fija una pauta de conducta como "sujeto obligado", desde la regulación del artículo 3.29 del Decreto Legislativo 1249, merece ser estudiado tomando como punto de partida la esfera de libertad protegida que no puede trastocar la pauta de conducta que se ha fijado para el abogado. Ello debido a que aún cuando se tenga una norma jurídica que fije una pauta de conducta sobre el abogado, y a partir de ésta deba entenderse el traslado de deberes como "sujeto obligado a informar operaciones sospechosas"; existe, por la jurisprudencia, el desarrollo sobre "la mínima lesividad del acto y las circunscias en que se efectuó" ${ }^{\prime \prime}$, como criterios para regular dicha exigencia; esto es, un ámbito o esfera que desde la Constitución y la jurisprudencia es abarcada por "el ejercicio legitimo de una profesión" llegando a reconocer como manifestación de aquél al "secreto profesional".

Esta extensión de la Cláusula imperativa sobre la acividad o intervención del abogado en la vida social, debe entenderse en el marco de un mundo donde los deberes, tanto negativos como positivos, han sido trasladados a personas capaces de convivir en sociedad sin dañar al otro en la esfera de libertades; y que, además de aquél deber general o negativo - no dañar a otro-, han de hacer posible, desde la especial posición que ostentan en la sociedad, el cumplimiento de deberes especiales o po- sitivos - de procurar o gestar la conservación del mandato especial-. Ésta última anotación, desde la antigua Grecia, inspiraba su forma de gobierno y podía traducirse en la siguiente expresión: "Indigno de vivir en sociedad, aquél que en desempeño de su cargo, observe una condcuta deshonesta"io.

A partir del traslado de deberes especiales o positivos para el abogado, desde el artículo 3.29 del Decreto Legislativo 1249, conviene aclarar que una indicación sobre su alcance está limitado por el "secreto profesional", así lo establece la propia ley, siendo ello compatible con la Constitución ${ }^{11}$. Esta cláusula restrictiva, a nuestro parecer, tiene una esfera que envuelve aquél ámbito de libertad que se supone siempre dentro del rol de abogado; en contra partida, no opera, como cláusula restrcitiva o de descarga, sobre aquella actuación que se realiza fuera del alcance del rol social de abogado. En consecuencia, no todo abogado, per se, está motivado por la pauta de conducta que transfiere el "deber de informar de operaciones sospechosas"; solamente, aquél que al momento de intervenir como abogado: Crea un riesgo que desde la lectura de la Ley 1106 puede dar lugar a que otro "convierta, transfiera, oculte o tenga" dinero de alguna actividad delictiva previa, dándole la apariencia de legalidad a los mismos.

Es poco claro, sin embargo, la lógica empleada

9. Casación N³74-2015-Lima.

10. DURRIEU, Roberto. El lavado de dinero en la Argentina. Argentina: Lexis Nexis, 2006, p. 63: "En base a lo expuesto cabe preguntarnos: ¿Es justo que se le exija a los particulares ciertas obligaciones que tradicionalmente fueron propias del Estado? En concreto, y sin extendernos demasiado más en nuestro análisis, cabe decir que el contexto internacional, así como también el Derecho comparado, nos enseñan en este caso que la posible vulneración del deber de guardar secreto mediante la imposición de reportar operaciones que pesa sobre algunos sujetos constituye una medida justificada y proporcional para la prevención y combate del blanqueo de capitales. Es decir, la comunidad internacional ha entendido en el balance de los derechos que resulta ser fundamental imponer obligaciones adicionales a ciertos particulares del mercado económico, en post de una contundente represión y prevención del delito de blanqueo de capitales".

11. Decreto Supremo N020-2017-JUS. Artículo 4,- Obligación de informar a la UIF-Perú: “(...) 4.1 Los sujetos obligados, cualquier entidad pública, persona jurídica o persona natural, están obligados a atender oportunamente las solicitudes de información que realice la UIF-Perú para el cumplimiento de sus funciones, incluyendo el acceso a registros, bancos o bases de datos con las que cuente, salvo la información que se encuentre dentro de las limitaciones establecidas en la Constitución Política del Perú, garantizando su exactitud y veracidad, considerando lo dispuesto en las normas reglamentarias que emita la SBS". 
por el legislador, para trasladar sobre algunos abogados el deber como "sujetos obligados a informar de operaciones sospechosas" y, sobre otros, conservar el escudo protector que supone "el secreto profesional" cuando éste es un deber que le asiste a todo abogado particular. Esta, si quiere llamarse así, diferencia que hace el legislador entre los abogados, a nuestro parecer, se inclina por un criterio según la cual es posible adverir la intervención del abogado desde dos escenarios: a) Intervención en el delito de lavado de activos como abogado adecuándose al ejercicio de la profesión, sin crear riesgos potenciales; y b) Intervención en el delito de lavado de activos como abogado "fuera del rol social de abogado", creando riesgos potenciales. Evidentemente, en ambas, la intervención es a partir de la condición especial que como abogado puede realizar el profesional, no obstante, la diferencia yace desde la función que desempeña aquél, en el caso concreto, usando la profesión, y que desde las circunstancias en que se efectuó la intervención, puede adquirir un significado fuera del rol social, fundamentando algo más que un simple deber de informar o denunciar los hechos que ha conocido.

De otro lado, siguiendo la línea que se ha establecido en la Casación N ${ }^{\circ}$ 374-2015-Lima: "Cuando se ejerce como abogado particular se puede dividir en tres: a) Actividades de transacción, b) Asesoria jurídica, c) Defensa en un proceso o procedimiento. En la primera el abogado presta sus servicios para constituir empresas, asumir la dirección de las mismas, actuar en conciliaciones, o negociar entre partes en conflicto al margen de alguna institución. La asesoría jurídica sirve para explicar al cliente los alcances jurídicos de una situación en este ámbito, los efectos de seguir adelante un proceso o expresarle la estrategia de litigación que se planea utilizar antes de ingresar a la defensa en el proceso. Producto de ello, la tercera actividad, es la defensa en juicio, que se da cuando el abogado brinda servicios en un juicio, que se da cuando el abogado brinda servicios en un proceso. Por lo que sus labores son amplias y puede desenvolverse en cualquiera de estos ámbitos".

A nuestro criterio, el haber convertido al abogado como sujeto obligado, dejando a salvo el secreto profesional, es el intento de una política que sobre especiales circunstacias, en el fondo, busca sancionar al abogado, no por omitir informar, sino que, tras haber establecido, en el ciclo de lavado, que aquél ha perdido la neutralidad en su intervención, busca atribuirle responsabilidad dentro del delito en cuestión. Esto debido a que frecuentemente se invoca la realización de una "conducta neutral" o un comportamiento dentro del "rol" que limita la posibilidad de castigar a un abogado que sirve de vehículo para el traslado del dinero ilícitamente obtenido de una esfera oscura a otra que en apariencia es lícita ${ }^{12}$.

En ese sentido, el secreto profesional abarca desde la confesión del cliente al abogado, hasta la prestasión del servicio que brinda, sin que este colisione con el ámbito de un riesgo no permitido. Por ejemplo, distintas son las situaciones cuando por un lado se tiene a quien busca un abogado para confesar que ha cometido un crimen y lo defienda frente a ello; $y$ por otro, respecto a quien busca a un abogado para confesar que desea matar a alguien, pero que para cuando tengan que defenderlo no consigan hallarlo culpable, le pide asesoría de cómo dejar menos evidencias del hecho. Evidentemente, en ambos supuestos el abogado hace uso de sus conocimientos legales,

12. BLANCO, Hernán. Lavado de activos por sujetos obligados. Análisis desde la teoría de los delitos de infraccion de deber. Buenos Aires: Abeledo Perrot, 2011, p. 44: "En tal sentido, D'Albora explica que en los casos en que la omisión de la obligación de informar coadyuve a la realización del tipo del art. 278, se produce la identidad estructural, desde perspectivas normativo-materiales, entre la omisión del deber de informar y la realización activa del precepto. Ello por cuanto - según entiende éste autor-sobre los abligados a informar pesa el deber jurídico del dominio sobre el riesgo típico de que se introduzcan en la economía legal activos de origen delictivo. Su decisión sobre el cumplimiento de la obligación es determinante para la producción del resultado". 
pero también es palpable la lesividad del acto sobre las circunstancias en las que efectuó la profesión ${ }^{13}$.

Entonces, es perfectamente posible valorar desde dos dimensiones la intervención del abogado. Con ocasión al delito de lavado de activos, una primera valoración de la intervención del abogado se debe referir al momento en el que conoce la información de su cliente para prestarle alguna asesoría o intervención como profesional, no obstante que aquél ha tomado conocimiento de la idea de "operaciones sospechosas" no podría denunciar por la sencilla razón de que la información ha sido transmitida a suerte de confesión. En contraposición, una segunda valoración de la intervención del abogado, se refiere a la puesta en marcha y ejecución de la "operación sospechosa" solicitada por su cliente. Ante esta última posibilidad, lo que corresponde es determinar la existencia de la minima lesividad del acto y las circunstancias en que se efectuó la conducta, con la finalidad de establecer una responsabilidad objetiva por la sola desatención del "deber de informar", o, si cabe, ante la verificación del deber quebrantado, la imputación por la comisión del delito de lavado de activos.

Finalmente, consideramos que el haber transferido "deberes especiales" al abogado en relación al delito de lavado de activos, sirve fundamentalmente para construir una imputación sobre la pérdida del "rol social". El abandono libre que decide el abogado al "rol social" surge por el del quebrantamiento a los "deberes especiales", lo que a su vez permite dejar atrás la idea que toda intervención del abogado en un acontecimiento de lavado supone siempre una conducta neutra.
La razón por la que se pierde la responsabilidad penal del abogado como sujeto obligado es porque su regulación describe un nexo de causalidad puramente objetivo, por lo que su sanción no puede ser de naturaleza penal. Además de ello, porque la prescripción de "obligación" a la que se somete supone un excesivo adelantamiento de las barreras de punibilidad, por sancionarse el conocer, sin que exista un potencial o real situación de peligro sobre el objeto que se busca tutelar. Asimismo, porque el derecho-deber del secreto profesional, se toma como una confesión del cliente y ello no puede ser susceptible de negación in abstracto.

El secreto profesional, sin embargo, se pierde cuando al ejercer la profesión se supera la mínima lesividad del acto, y por las circunstancias en las que se efectuó la intervención del abogado, no solo como confesor, sino como agente activo del plan del cliente, incrementa el riesgo contribuyendo a la finalidad de aquél, es decir, a evitar la identificación real de los activos sobre los que realiza cuales quiera de las funciones propias de la profesión de abogado. Solo bajo este contexto es posible invocar que no se actuó dentro del "rol" de abogado, y por el contrario, cuestionar una intervención del abogado como vehículo para conducir dinero obtenido de la comisión de un delito previo a una esfera lícita procurando que no se identifique su origen ilícito.

Por eso consideramos que la verdadera finalidad de la imposición de una pauta de conducta para el abogado está orientado a establecer un deber del cual sea posible argumentar el incremento del riesgo que administrativamente regula como "obligación a informar" de operaciones sospechosas que, si bien puede llegar a conocer, por una cláusula de confidencialidad,

13. CÁLIX VALLECILLO, Carlos David. El delito de blanqueo de capitales en el Código Penal Español. Bogota: Ediciones Doctrina y Ley, 2010, p. 222: "Y es que tomando en cuenta que el delito de blanqueo de capitales admite las formas omisivas puede suceder que (...) invocando el deber de guardar silencio sobre las operaciones concertadas con sus clientes, callen y se abstengan de informar sobre éstas al Servicio Ejecutivo, infringiendo con ello las disposiciones de la Ley 19/1993 y facilitando así la ejecución de una operación dirigida a ocultar el origen delictivo de los bienes, su destino, ubicación, movimiento, etc (...), o en su caso, ayudar a los intervinientes en el delito previo a eludir las consecuencias jurídicas de sus acciones". 
no necesariamente debe denunciar. Aunque la anotación antes indicada sirve de referencia cuando el abogado, además de conocer la operación sospechosa a la cual su cliente le ha invitado participar aportando instrumentos que solo su profesión pueden hacer posible, incrementa el riesgo aportando al hecho reales circunstancias que se reflejan de la indiferencia que muestra las operaciones sospechosas que como traslado del "deber de informar" se le exige comunicar, o al menos, dentro de su libertad, decidir por no transgredir la línea delgada que separa lo permitido de lo no permitido.

Por lo tanto, la puerta que abre paso a que se abandone el argumento de que todo abogado inmerso en un hecho de lavado de activos, siempre actúa "conforme a su rol" puede cambair de rumbo si es que, de ahora en adelante, para analizar la relevancia penal de la intervención del abogado, se toma en cuenta los deberes de solidaridad del abogado, exigibles para no incrementar el riesgo dentro de las llamadas "operaciones sospechosas". 